\title{
APPLICATION OF CIDER BY-PRODUCTS FOR MEDIUM CHAIN LENGTH POLYHYDROXYALKANOATE PRODUCTION BY PSEUDOMONAS PUTIDA KT2440
}

DOI:

10.1016/j.eurpolymj.2018.08.020

\section{Document Version \\ Accepted author manuscript}

Link to publication record in Manchester Research Explorer

Citation for published version (APA):

Urbina, L., Wongsirichot, P., Corcuera, M. Á., Gabilondo, N., Eceiza, A., Winterburn, J., \& Retegi, A. (2018). APPLICATION OF CIDER BY-PRODUCTS FOR MEDIUMM CHAIN LENGTH POLYHYDROXYALKANOATE PRODUCTION BY PSEUDOMONAS PUTIDA KT2440. European Polymer Journal, 108, 1-9. https://doi.org/10.1016/j.eurpolymj.2018.08.020

\section{Published in:}

European Polymer Journal

\section{Citing this paper}

Please note that where the full-text provided on Manchester Research Explorer is the Author Accepted Manuscript or Proof version this may differ from the final Published version. If citing, it is advised that you check and use the publisher's definitive version.

\section{General rights}

Copyright and moral rights for the publications made accessible in the Research Explorer are retained by the authors and/or other copyright owners and it is a condition of accessing publications that users recognise and abide by the legal requirements associated with these rights.

\section{Takedown policy}

If you believe that this document breaches copyright please refer to the University of Manchester's Takedown Procedures [http://man.ac.uk/04Y6Bo] or contact uml.scholarlycommunications@manchester.ac.uk providing relevant details, so we can investigate your claim.

\section{OPEN ACCESS}


1 APPLICATION OF CIDER BY-PRODUCTS FOR MEDIUM CHAIN LENGHT POLYHYDROXYALKANOATE PRODUCTION BY PSEUDOMONAS PUTIDA

$3 \quad$ KT2440

4 Leire Urbina ${ }^{1}$, Phavit Wongsirichot ${ }^{2}$, María Ángeles Corcuera ${ }^{1}$, Nagore Gabilondo ${ }^{1}$, 5 Arantxa Eceiza ${ }^{1}$, James Winterburn ${ }^{2}$, Aloña Retegi ${ }^{1, *}$

6

7

' 'Materials + Technologies' Group, Engineering School of Gipuzkoa. Department of Chemical and Environmental Engineering, University of the Basque Country (UPV/EHU), Pza. Europa 1. Donostia - San Sebastian 20018, Spain.

${ }^{2}$ School of Chemical Engineering and Analytical Science, The Mill, The University of Manchester, Manchester M13 9PL, UK.

(leire.urbina@ehu.eus; phavit.wongsirichot@postgrad.manchester.ac.uk; marian.corcuera@ehu.eus; nagore.gabilondo@ehu.eus ; arantxa.eceiza@ehu.eus; james.winterburn@manchester.ac.uk; alona.retegui@ehu.eus)

(*Corresponding author: Aloña Retegi: alona.retegui@ehu.eus; 943017187)

\begin{abstract}
In this study the technical feasibility of using cider by-products as a substrate for the production of medium chain length polyhydroxyalkanoates (mcl-PHAs) by Pseudomonas putida KT2440 is demonstrated. The untreated apple pomace was found to be composed of two main residual sugars, glucose and fructose, making it a promising cheap growth substrate. A PHA concentration of $1.1 \mathrm{~g} \mathrm{~L}^{-1}$ and a PHA accumulation of $25.5 \%$ were obtained in flask experiments using apple pomace as the sole carbon source without any pretreatment, employing a fed batch strategy. The biopolymer was extracted from the biomass and a detailed characterization was carried out. The solution-casted film was found to be a mcl-PHA copolymer composed by different saturated and unsaturated ester monomers with elastomeric characteristics making it suitable for applications in biomedicine or the processing of value added coproducts such as environmentally friendly adhesives or biodegradable films for agricultural purposes.
\end{abstract}

\title{
Keywords
}

Cider by-products, waste utilization, Pseudomonas putida KT2440, mcl-PHA, elastomeric biopolymer

\section{INTRODUCTION}

Polyhydroxyalkanoates (PHA), biopolyesters synthesized by numerous microorganisms as intracellular carbon and energy storage compounds, are gaining special attention as they are considered a green alternative to conventional petroleum-based plastics ${ }^{[1]}$. Medium-chain-length PHAs (mcl-PHAs) that contain 6-14 carbon atoms in their monomeric units, are produced by Pseudomonas strains. It has been previously reported that these bacteria can biosynthesize saturated and unsaturated monomers, which in combination with long chains, leads to highly amorphous polymers ${ }^{[2-4]}$. Moreover, there are several studies that demonstrate the biocompatibility of these polymers ${ }^{[5,6]}$. For these reasons mcl-PHAs are considered to be attractive in the biomedical field for applications in which elastomeric and flexible materials are needed in contact with soft 
tissue, such as skin tissue engineering, controlled drug delivery or vascular applications ${ }^{[7,8]}$. Mcl-PHAs can also be used as binders in paints, as adhesives, in the food area for covers and in natural fibre composites since they present better adherence to natural fibres compared to conventional polyolefin matrixes ${ }^{[9]}$. Pseudomonas strains show potential as they can assimilate a wide range of both, structurally related (fatty acids) and unrelated (glucose, glucanoate, fructose and glycerol) carbon sources due to their catabolic versatility and genetic diversity. The structurally unrelated carbon sources are considered less toxic and less expensive than the fatty acids used so far, which can lead to a reduction of production costs opening up the possibility of large scale production ${ }^{[10]}$. In this context, agrowastes and residues from the food industry are good candidates for PHA production since they offer abundant and inexpensive carbon source. There is a large open field to convert food waste or by-products in PHAs and different wastes have been proposed to date, such as whey, starch, oils, spent coffee grounds, pea-shell slurry, etc ${ }^{[11,12]}$.

Apple pomace is the main by-product of apple juice and cider production and represents around the $25-30 \%$ of the weight of the original fresh fruit. Apple pomace is heterogeneous and consists of peel, core, seeds, calyx, stem, exhausted soft tissue and also discarded apples. The wet apple pomace is biodegradable with high levels of biochemical oxygen demand and it is a voluminous waste with high water and fermentable sugar contents resulting in a quick spoilage in landfills, so its disposal causes serious environmental problems. Nowadays, the cider production is widespread worldwide, therefore it is important to search for methods of recovery and management of this waste, since apart from the traditional use as cattle feed, there are not many routes for the valorization of this by-product. Concretely, in Spain more than 20,000 metric tonnes of apple pomace are produced every year as a by-product of cider production, with Asturias being the largest producer, followed by the Basque Country $^{[13]}$. Although the composition of the apple pomace varies depending on different factors it contains minerals, is rich in nutrients and also contains a large amount of carbohydrates, of which about $70 \%$ are simple sugars, with fructose being the predominant sugar, followed by glucose, sucrose, arabinose, galactose and xylose ${ }^{[14]}$. Taking these features into account, cider by-products could be considered a good substrate for PHA production.

This work aims to give an understanding of the feasibility of producing mcl-PHAs with Pseudomonas putida using cider by-products and to develop a bioprocess to maximize the PHA production using these residues as the only carbon source. The results obtained confirm the possibility of using untreated apple pomace (no saccharification or pretreatment) as feedstock for PHA production, potentially making the process more economically viable compared to using fatty acids, while decreasing the volume of apple waste. For the first time the viability of cider apple pomace as a cheap and sustainable carbon substrate for mcl-PHA production is demonstrated using Pseudomonas putida KT2440. The biosynthesized polymer was extracted from the biomass and the solvent casted film was characterized. Characteristic chemical groups, monomeric composition and chemical structure of the mcl-PHA were determined by Fourier transform infrared (FTIR) spectroscopy, gas chromatography-mass spectrometry (GC-MS) and nuclear magnetic resonance spectroscopy $\left({ }^{1} \mathrm{H}\right.$ and ${ }^{13} \mathrm{C}$ NMR), respectively. In addition, molecular weight, physical and thermal properties have been evaluated to assess the suitability of using the obtained PHA in different applications in the biomedical and agricultural fields or in food packaging. 


\section{MATERIALS AND METHODS}

\subsection{Microbial strain}

In this study Psedomonas putida KT2440 (P. putida) bacterial strain was acquired from The Leibniz Institute DSMZ, Germany. Master and working stocks were created from the lyophilised cells as per instruction provided by the supplier, and stored at $-80{ }^{\circ} \mathrm{C}$ prior to reactivation and use in experiments.

\subsection{Inocula and media preparation}

For the preparation of inocula, cells from cryo-storage were reactivated using nutrient agar plates (Sigma Aldrich, UK) prior to each experiment. A single colony of $P$. putida from the petri dish was used to inoculate $10 \mathrm{~mL}$ of minimal medium, which was grown at $30{ }^{\circ} \mathrm{C}$ at $200 \mathrm{rpm}$ for $24 \mathrm{~h}$. This medium was transferred to $100 \mathrm{~mL}$ of identical medium $(10 \% \mathrm{v} / \mathrm{v})$ in Erlenmeyer flasks, incubated as above and used to inoculate the apple waste juice media ( $10 \%$ of the working volume). The minimal medium formulation ${ }^{[15]}$ contained per litre: $7.5 \mathrm{~g} \mathrm{~K}_{2} \mathrm{HPO}_{4}, 3.7 \mathrm{~g} \mathrm{KH}_{2} \mathrm{PO}_{4}, 2.38 \mathrm{~g} \mathrm{Na}_{2} \mathrm{HPO}_{4}, 0.89$ $\mathrm{g} \mathrm{NH}_{4} \mathrm{Cl}$ and $2.9 \mathrm{~g} \mathrm{Na}_{3} \mathrm{C}_{6} \mathrm{H}_{5} \mathrm{O}_{7} \cdot 2 \mathrm{H}_{2} \mathrm{O}$ as carbon source. The $\mathrm{pH}$ was adjusted to 7.1 with $1 \mathrm{M} \mathrm{NaOH}$. This medium was autoclaved and subsequently supplemented with $1 \mathrm{~mL} \mathrm{~L}^{-}$ ${ }^{1}$ of $0.2 \mathrm{~g} \mathrm{~L}^{-1} \mathrm{MgSO}_{4} \cdot 7 \mathrm{H}_{2} \mathrm{O}$ solution, filter sterilised, and $1 \mathrm{~mL} \mathrm{~L}^{-1}$ filter sterilised MT (mineral trace element) stock solution of $1 \mathrm{M} \mathrm{HCl}$ which contained $2.78 \mathrm{~g} \mathrm{~L}^{-1}$ $\mathrm{FeSO}_{4} \cdot 7 \mathrm{H}_{2} \mathrm{O}, 1.47 \mathrm{~g} \mathrm{~L}^{-1} \mathrm{CaCl}_{2} \cdot 2 \mathrm{H}_{2} \mathrm{O}, 1.98 \mathrm{~g} \mathrm{~L}^{-1} \mathrm{MnCl}_{2} \cdot 4 \mathrm{H}_{2} \mathrm{O}, 2.81 \mathrm{~g} \mathrm{~L}^{-1} \mathrm{CoSO}_{4} \cdot 7 \mathrm{H}_{2} \mathrm{O}$, $0.17 \mathrm{~g} \mathrm{~L}^{-1} \mathrm{CuCl}_{2} \cdot 2 \mathrm{H}_{2} \mathrm{O}, 0.29 \mathrm{~g} \mathrm{~L}^{-1} \mathrm{ZnSO}_{4} \cdot 7 \mathrm{H}_{2} \mathrm{O}$ and $0.2 \mathrm{~g} \mathrm{~L}^{-1} \mathrm{MgSO}_{4} \cdot 7 \mathrm{H}_{2} \mathrm{O}$. The chemicals in all experiments were purchased from Sigma-Aldrich. Sterile conditions were maintained throughout the experiments, and all the stock solutions used were either sterile filtered using $0.45 \mu \mathrm{m}$ Nalgene ${ }^{\mathrm{TM}}$ Rapid-Flow $^{\mathrm{TM}}$ membrane filtration units (Thermo Fisher, UK) or autoclaved.

The apple medium was prepared with a mixture of apple residues collected from a cider producer in Gipuzkoa (Northern Spain) consisting of peel, seeds, core, stems, exhausted soft tissue and also discarded apples. The raw material was stored at $-20{ }^{\circ} \mathrm{C}$ until use. This medium was prepared with crushed and squeezed apple residues in a commercial blender with distilled water at room temperature with different solid:liquid ratios indicated in the next section. Then it was filtered and centrifuged for $10 \mathrm{~min}$ at 7000 rpm to remove the solids. Salts were added directly to the juice to obtain the enriched apple residue juice: $7.5 \mathrm{~g} \mathrm{~K}_{2} \mathrm{HPO}_{4}, 3.7 \mathrm{~g} \mathrm{KH}_{2} \mathrm{PO}_{4}, 2.38 \mathrm{~g} \mathrm{Na}_{2} \mathrm{HPO}_{4}$ and $0.89 \mathrm{~g} \mathrm{NH}_{4} \mathrm{Cl}$. The $\mathrm{pH}$ was adjusted to 7.1 with $1 \mathrm{M} \mathrm{NaOH}$. Afterwards, the medium was sterilized by filtration using $0.45 \mu \mathrm{m}$ Nalgene ${ }^{\mathrm{TM}}$ Rapid-Flow $^{\mathrm{TM}}$ membrane filtration units (Thermo Fisher, UK). Finally, filter sterilized $\mathrm{MgSO}_{4}$ and $\mathrm{MT}$ were supplemented as above.

A control medium was prepared for comparison of PHA production and total biomass over time with the apple juice media. The control medium for shake flask experiments contained $3 \mathrm{~g} \mathrm{~L}^{-1}$ and $10 \mathrm{~g} \mathrm{~L}^{-1}$ of commercial glucose and fructose, respectively, as carbon sources. These sugars and concentrations were chosen to mimic the most concentrated apple juice medium obtained. The $\mathrm{pH}$ was adjusted as above before autoclaving. Then, the medium was supplemented with sterile salts, filter sterilized $\mathrm{MgSO}_{4}$ and $\mathrm{MT}$ as above.

\subsection{Shake flask experiments}


All the experiments were conducted in duplicate in $1 \mathrm{~L}$ Erlenmeyer shake flasks with a working volume of $200 \mathrm{~mL}$. The cultures were incubated at $30{ }^{\circ} \mathrm{C}$ in an orbital shaker at $200 \mathrm{rpm}$.

The first experiment was conducted to confirm the capability of $P$. putida to utilize these residues to produce PHAs and check for cell growth inhibitory effects. For this different apple waste to water $(\mathrm{AW}: \mathrm{W})$ ratios $(0.4: 1,1: 1$ and $1.5: 1)$ were used to prepare juices with different concentration of sugars and determine the optimum ratio for the maximum PHA production. Total nitrogen (TN), glucose and fructose concentration and optical density were measured during $72 \mathrm{~h}$ of cultivation. PHA concentration was checked at the $72 \mathrm{~h}$ mark. Additionally, a control culture prepared with commercial glucose and fructose was also tested.

The second experiment was carried out in shake flasks in order to establish a batch feeding strategy to maximize the PHA production. More concentrated apple juice was prepared with the best $\mathrm{AW}: \mathrm{W}$ ratio obtained from the first experiment. $20 \mathrm{~mL}$ of the same apple juice with salts were supplemented in each culture at different cultivation times in order to increase the PHA production. In the experiment A the extra feed was added at $12 \mathrm{~h}$ of fermentation, in the experiment $\mathrm{B}$ at $24 \mathrm{~h}$ of fermentation and in the experiment $\mathrm{C}$ at $48 \mathrm{~h}$ of fermentation. Total nitrogen, glucose and fructose concentration and optical density were measured during $96 \mathrm{~h}$ of cultivation. PHA concentration was quantified at the $96 \mathrm{~h}$ mark.

\subsection{Analytical methods}

Total biomass over time was monitored measuring the optical density $\left(\mathrm{OD}_{600}\right)$ at 600 $\mathrm{nm}$ using a spectrophotometer, UV-mini1240 (Shimadzu, USA). 1-2 $\mathrm{mL}$ of the culture sample was transferred to an Eppendorf tube and centrifuged at $13000 \mathrm{rpm}$ for $5 \mathrm{~min}$ at room temperature. The supernatant was stored at $-20{ }^{\circ} \mathrm{C}$ prior to further analysis while the cell pellet was resuspended in $0.7 \% \mathrm{NaCl}$ solution to measure the optical density.

The total biomass was estimated gravimetrically as dry cell weight (DCW). 5-10 mL of fermented broth obtained from shake flasks was centrifuged at $5000 \mathrm{rpm}$ for $15 \mathrm{~min}$. The cell pellet was resuspended in a small quantity of distilled water and dried at $50{ }^{\circ} \mathrm{C}$ using labelled, dried and pre-weighted aluminium plates to estimate the final DCW.

PHA quantification and composition was determined by methanolysis and gas chromatography (GC). Methanolysis was carried out according to modified method reported by Lageveen et al. ${ }^{[15]} .10 \mathrm{mg}$ of biomass were dissolved in $2 \mathrm{~mL}$ of $\mathrm{CH}_{2} \mathrm{Cl}_{2}$ and then $2 \mathrm{~mL}$ of $\mathrm{CH}_{3} \mathrm{OH}: \mathrm{H}_{2} \mathrm{SO}_{4}(85: 15 \mathrm{v} / \mathrm{v})$ mixture were added into the vial and incubated at $100{ }^{\circ} \mathrm{C}$ for $140 \mathrm{~min}$, then cooled to room temperature. Around $1 \mathrm{~mL}$ of distilled water was added and vigorously vortexed with the resulting solution being allowed to stand for $10 \mathrm{~min}$. The bottom organic layer was separated and filtered (nylon filters of 0.22 $\mu \mathrm{m}$ ) into $\mathrm{GC}$ vials and remaining $\mathrm{H}_{2} \mathrm{O}$ content was removed. A gas chromatography system model 7820A (Agilent Technologies, USA) with a SGE BPX5 column $(30 \mathrm{~m} \times 0.25 \mathrm{~mm} \times 0.25 \mu \mathrm{m})$ with helium as the carrier gas and flame ionization detection (FID) was used. The injection volume was $5 \mu \mathrm{L}$ in split mode (split ratio 10:1). The initial temperature was $100^{\circ} \mathrm{C}$, increased gradually at $25^{\circ} \mathrm{C} \mathrm{min}^{-1}$, and the 
detection temperature was $300{ }^{\circ} \mathrm{C}$. Standards of known concentrations were used for comparison of the peak areas.

The concentration of glucose and fructose in the supernatant collected from the samples at different cultivation times was determined using Dionex Ultimate 3000 high performance liquid chromatography (HPLC) equipment. Samples were filtered using $0.45 \mu \mathrm{m}$ nylon filters prior to analysis. The refractive index intensity of the samples was measured using a RefractoMax 521 (ThermoFisher Scientific, UK) detector, set at 50 ${ }^{\circ} \mathrm{C}$, peak area and concentration were correlated using a calibration curve constructed by running standards of known concentration. An Aminex HPX-87H column was used to achieve the separation at a temperature of $50^{\circ} \mathrm{C}$. An isocratic flow of $0.6 \mathrm{~mL} \mathrm{~min}{ }^{-1}$ was used with $5 \mathrm{mM} \mathrm{H}_{2} \mathrm{SO}_{4}$ as an eluent, and $20 \mu \mathrm{L}$ injection was used.

The amount of total nitrogen (TN) was determined using a total nitrogen analyser unit (TNM-1) attached to a TOC-control V organic carbon unit (Shimazdu, Japan). An aliquot of $250 \mu \mathrm{L}$ of solid-free supernatant was diluted to a final volume of $20 \mathrm{~mL}$ and filtered through $0.45 \mu \mathrm{m}$ pore nylon filters before analysis. Standards of $\mathrm{KNO}_{3}$ were used for calibration.

\subsection{Calculations}

The PHA proportion of total biomass was evaluated at the end of the fermentation process, as a concentration, mass of PHA per litre of fermentation broth, and as a percentage of total biomass (PHA (\%)) (Eq. 1). The yield coefficient of cell biomass $\left(Y_{X / S}\right)$ was determined based on the amount of active biomass formed $(\Delta X)$ per total mass substrate (glucose + fructose) consumed $(\Delta S)$ (Eq. 2) and the product yield coefficient $\left(Y_{P / S}\right)$ was calculated based on the amount of PHA produced at the end of the fermentation per total mass substrate consumed $(\Delta S)$ (Eq. 3$)$.

$$
\text { PHA }(\%)=\frac{\text { PHA } \text { produced }}{\text { total } \text { biomass }} \cdot 100
$$

$$
Y_{X / S}=\frac{\Delta X}{\Delta S}=\frac{\text { mass cells produced }}{\text { mass substrate consumed }}=\frac{D C W_{\text {final }}-D C W_{0}-P H A \text { produced }}{\text { mass substrate consumed }}\left(\frac{g}{g}\right)
$$

\subsection{Polymer extraction and purification}

PHA was extracted from the bacterial biomass using the method developed by Jiang et al. ${ }^{[16]}$. The recovery process was based in three steps. Firstly, pretreatment of the biomass, then Soxhlet extraction with acetone and finally purification of the PHA with methanol. Firstly, about $2 \mathrm{~g}$ of dried biomass were vortex mixed with $40 \mathrm{~mL}$ of methanol for $5 \mathrm{~min}$ at room temperature to make the PHA more pure, accessible and soluble for the extraction step. The methanol treated biomass was then centrifuged for 5 
min at $7000 \mathrm{rpm}$ and then dried at $40{ }^{\circ} \mathrm{C}$. The pretreatment was followed by Soxhlet extraction with $120 \mathrm{~mL}$ acetone for $5 \mathrm{~h}$. Then, the solution was concentrated by rotary evaporation at $40{ }^{\circ} \mathrm{C}$. Finally, the acetone containing bioplastic solution was added drop-wise into cold methanol (acetone:methanol 1:10 (v/v)) under agitation. After polymer precipitation, the solution was centrifuged at $9000 \mathrm{rpm}$ for $30 \mathrm{~min}$. The liquid was carefully eliminated with a syringe and the plastic was dissolved with chloroform and finally dried at room temperature in a Teflon plate to obtain the PHA film.

\subsection{Polymer characterization}

\subsubsection{Molecular weight analysis}

Gel permeation chromatography (GPC) was used to calculate weight average and number average molecular weights, $\bar{M}_{w}$ and $\bar{M}_{n}$, respectively, and polydispersity index (PI) of the biosynthesized PHA. A Thermo Scientific chromatograph, equipped with an isocratic Dionex UltiMate 3000 pump and a RefractoMax 521 refractive index detector was used. The separation was carried out at $30^{\circ} \mathrm{C}$ within four Phenogel GPC columns from Phenomenex, with $5 \mu \mathrm{m}$ particle size and $10^{5}, 10^{3}, 100$ and $50 \AA$ porosities, respectively, located in a UltiMate 3000 Thermostated Column Compartment. Tetrahydrofuran (THF) was used as mobile phase at a flow rate of $1 \mathrm{~mL} \mathrm{~min}^{-1}$. Samples were prepared by dissolving PHA in THF at $1 \mathrm{wt} \%$ and filtering using nylon filters with a $2 \mu \mathrm{m}$ pore size. $\bar{M}_{w}$ and $\bar{M}_{n}$ were reported as weight average polystyrene standards.

\subsubsection{FTIR spectroscopy}

The characteristic groups present in the PHA were analyzed by Fourier transform infrared (FTIR) spectroscopy using a Nicolet Nexus spectrophotometer equipped with a MKII Golden gate accessory (Specac) with diamond crystal at a nominal incidence angle of $45^{\circ}$ and $\mathrm{ZnSe}$ lens. Spectra were recorded in attenuated reflexion (ATR) mode between $4000-650 \mathrm{~cm}^{-1}$ averaging 32 scans with a resolution of $4 \mathrm{~cm}^{-1}$.

\subsection{3. ${ }^{13} \mathrm{C}$ and ${ }^{1} \mathrm{H}$ NMR spectroscopy}

The chemical structure of the PHA produced using cider by products was investigated using proton $\left({ }^{1} \mathrm{H}\right)$ and carbon $\left({ }^{13} \mathrm{C}\right)$ NMR analysis. PHA samples were dissolved in deuterated chloroform $\left(\mathrm{CDCl}_{3}\right)$ prior to analysis. RMN ${ }^{13} \mathrm{C}$ and ${ }^{1} \mathrm{H}$ NMR measurements were conducted with a Bruker Avance 500 spectrometer, equipped with a BBO probe with gradient in $\mathrm{Z}$ axis. The spectrum was recorded using sequence zg Bruker library at 125.77 MHz. For the ${ }^{13} \mathrm{C}$ NMR measurements a time domain of $64 \mathrm{~K}$ was used in a spectral width of $31000 \mathrm{~Hz}$. An interpulse delay of $2 \mathrm{~s}$ was employed for and acquisition time of $1.5 \mathrm{~s}$ averaging $32 \mathrm{~K}$ scans. For the ${ }^{1} \mathrm{H}$ NMR measurements a time domain of $64 \mathrm{~K}$ was used in a spectral width of $10000 \mathrm{~Hz}$. An interpulse delay of $2 \mathrm{~s}$ was employed for and acquisition time of $3 \mathrm{~s}$ averaging $64 \mathrm{~K}$ scans.

\subsubsection{Determination of monomer composition by gas chromatography-mass spectrometry}

PHA monomeric composition was identified by GC-MS analysis of the methanolyzed polymer. Methanolysis was carried out as described previously. In this case $10 \mathrm{mg}$ of extracted and purified PHA were dissolved in the reagent mixture $\left(2 \mathrm{~mL}\right.$ of $\mathrm{CH}_{2} \mathrm{Cl}_{2}$ and 
then $2 \mathrm{~mL}$ of $\mathrm{CH}_{3} \mathrm{OH}: \mathrm{H}_{2} \mathrm{SO}_{4}(85: 15 \mathrm{v} / \mathrm{v})$ mixture) and treated as above. About $2 \mu \mathrm{L}$ of methanolyzed sample was automatically injected into the column (J\&W 122-7032: 2724.40537 DB-WAX). Oven temperature was programmed at $40{ }^{\circ} \mathrm{C}$ for 2 min and then increased to $240^{\circ} \mathrm{C}$ at $5{ }^{\circ} \mathrm{C} \mathrm{min}^{-1}$ and maintained for $15 \mathrm{~min}$.

\subsubsection{Differential scanning calorimetry}

Thermal properties were studied by differential scanning calorimetry (DSC) using a Mettler Toledo $822^{\mathrm{e}}$ equipment, equipped with a robotic arm and an electric intracooler as the refrigerator unit. An aluminium pan containing sample $(5-10 \mathrm{mg})$ was heated from -75 to $200{ }^{\circ} \mathrm{C}$ at a scanning rate of $20{ }^{\circ} \mathrm{C} \mathrm{min}$ m $^{-1}$ in a nitrogen atmosphere. Glass transition temperature was determined as the inflection point of the heat capacity change, whereas melting temperature and enthalpy were established as the maximum and the area under the endotherm peak, respectively.

\subsubsection{Dynamic mechanical analysis}

Thermomechanical behaviour was analyzed by dynamic mechanical analysis (DMA) using an Eplexor $100 \mathrm{~N}$ analyzer, Gabo equipment. Tensile mode measurements were carried out from -100 to $100{ }^{\circ} \mathrm{C}$ at a scanning rate of $2{ }^{\circ} \mathrm{C} \mathrm{min}^{-1}$. The static strain was established as $0.05 \%$ and the operating frequency was fixed at $1 \mathrm{~Hz}$.

\section{RESULTS AND DISCUSSION}

\subsection{PHA production}

The main objective of this work was to assess the feasibility of using not pretreated cider by-products (Fig. 1 a)) as the sole carbon source for the production of PHAs by $P$. putida KT2440. Shake flask experiments were carried out to explore the possibility of increasing the polymer concentration and accumulation by producing the most suitable media for fermentation and finally, the extraction and characterization of the PHA produced was performed in order to examine its possible film applications in different fields.

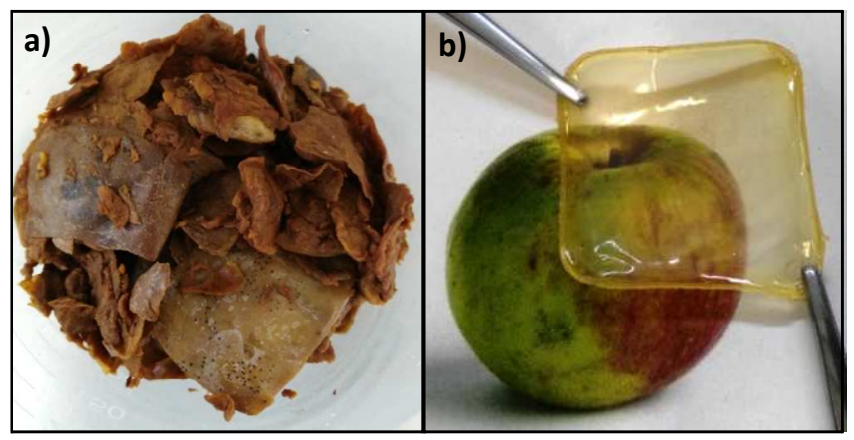

Fig. 1. a) Cider by-products used in this work and b) mcl-PHA film obtained using cider by-products as the only carbon source.

In the first experiment, waste apple juice fermentation media were prepared using different apple waste to water ratios (AW:W) and were analyzed in terms of sugar 
content. The AW:W ratios used were $0.4: 1,1: 1$ and 1.5:1. The apple waste juices were analyzed by HPLC and found to contain a mixture of mainly glucose and fructose, the latter being the main carbohydrate present (Table 1). Fructose yields were 0.75, 0.70 and $0.65 \mathrm{~g} \mathrm{~g}^{-1}$ for $0.4: 1,1: 1$ and 1.5:1 ratios, respectively. It was found that an AW:W ratio either below or above $1: 1$ resulted in a decrease of the carbohydrate extracted. In the case of a 1.5:1 ratio, there was not enough water to extract the sugars, suggesting that much unextracted soluble waste would be left. Therefore, in this case the optimum ratio for the highest extraction of carbohydrates was 1:1. For the fermentation experiments control cultures were prepared with commercial glucose and fructose with the similar concentrations obtained in the apple waste juice prepared with 1:1 ratio as a reference. Initial glucose, fructose and total nitrogen concentrations and $\mathrm{C} / \mathrm{N}$ ratios in each media are indicated in Table 1.

Table 1. Initial glucose, fructose and total nitrogen concentrations and $\mathrm{C} / \mathrm{N}$ ratios for the different $\mathrm{AW}: \mathrm{W}$ juices and control media.

\begin{tabular}{ccccc}
\hline & & \multicolumn{3}{c}{$\mathbf{A W}: \mathbf{W}$} \\
\cline { 3 - 5 } & Control & $\mathbf{0 . 4 : 1}$ & $\mathbf{1 : 1}$ & $\mathbf{1 . 5 : 1}$ \\
\hline Glucose $\left(\mathrm{g} \mathrm{L}^{-1}\right)$ & 3 & 1.2 & 2.5 & 1.8 \\
Fructose $\left(\mathrm{g} \mathrm{L}^{-1}\right)$ & 10 & 3.7 & 7.5 & 3.3 \\
Nitrogen $\left(\mathrm{g} \mathrm{L}^{-1}\right)$ & 0.22 & 0.18 & 0.21 & 0.21 \\
$\mathrm{C} / \mathrm{N}(\mathrm{mol} / \mathrm{mol})$ & 27 & 13 & 23 & 11 \\
\hline
\end{tabular}

341

342

343

344

345

346

Both glucose and fructose have proven to be adequate substrates for Pseudomonas strains ${ }^{[2]}$. Davis et al. ${ }^{[17]}$ used glucose as sole carbon source to achieve high cell density in fed batch bioprocesses. Escapa et al. ${ }^{[18]}$ compared the growth of P. putida KT2440 on different carbon sources i.e. acetate, citrate, pyruvate, succinate, gluconate, glucose, fructose and glycerol in flask experiments and they obtained the highest biomass yield on fructose. Moreover, mixtures of both sugars have been tested for PHA production and it was found that high cell density and high PHA amount in the biomass could be obtained using carbohydrates as the sole carbon source ${ }^{[19]}$. This suggests that cider byproducts can be suitable substrates for fermentation with $P$. putida KT2440.

All shake flask experiments were done in duplicate and total nitrogen, glucose and fructose concentration and cell biomass were measured during $72 \mathrm{~h}$ of cultivation, average values are displayed in Fig. 2. PHA content was measured at the end of the fermentation. As it can be seen in Fig. 2, P. putida bacterium is able to grow in the apple waste juice media with different sugar concentrations, with minimal inhibitory effects being observed. It is commonly known that cider apples are rich in polyphenolic compounds which are retained in the pomace and show antibacterial activity ${ }^{[20,21]}$. Apple cultivars and processing conditions affect the extractability of these compounds and their presence can influence the microbial growth, as it has been observed in the case of other fruit pomaces by Follonier et al. ${ }^{[22]}$. They observed complete inhibition of the cell growth at high concentrations of cherry hydrolyzed pomace, while no significant changes in the maximum specific growth rate of the cells was detected for high concentrations of apricot and grape pomaces. In this work the phenolic compounds which are probably present in the juice, do not seem to negatively affect the fermentation since both total biomass and PHA concentrations are reasonable and in the expected range. This could be due to the method used to extract the sugars of the apple pomace, since water at room temperature has been used, and the phenolic compounds are usually extracted using organic solvents or thermal treatments. 
a) Control

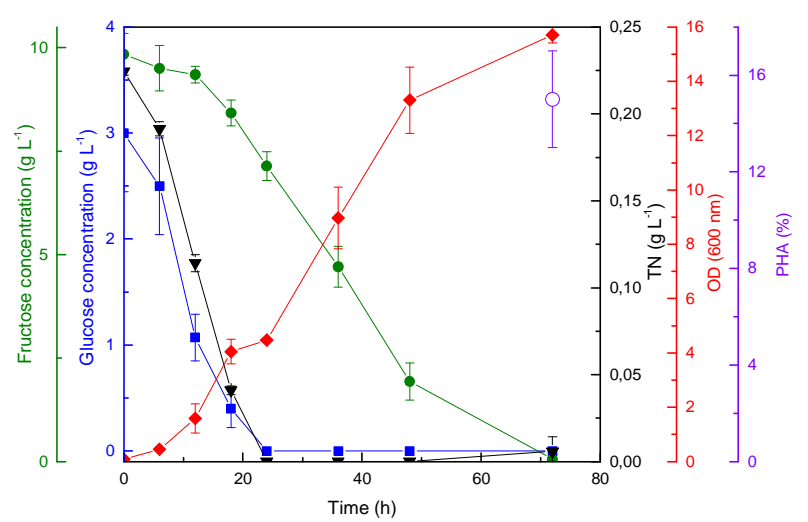

c) $A W: W=1: 1$

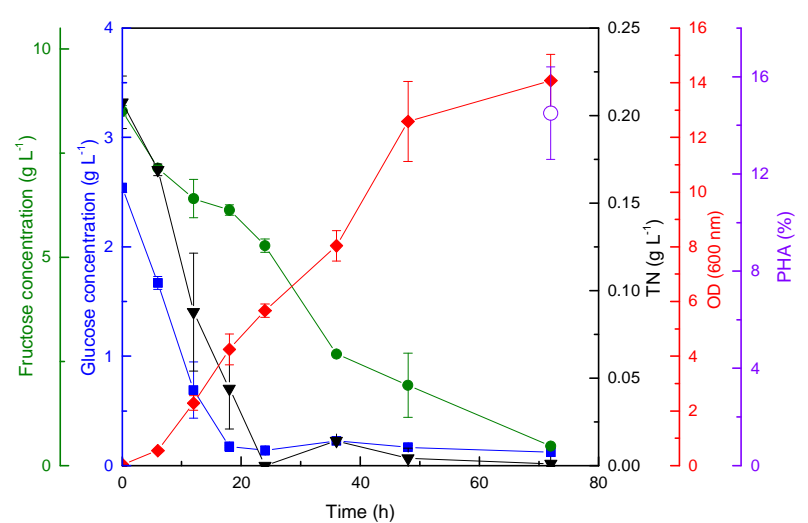

b) $A W: W=0.4: 1$

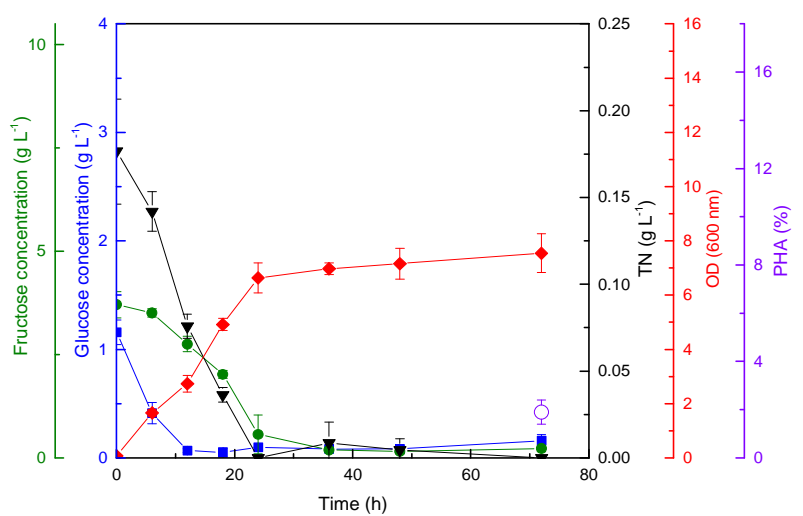

d) $A W: W=1.5: 1$

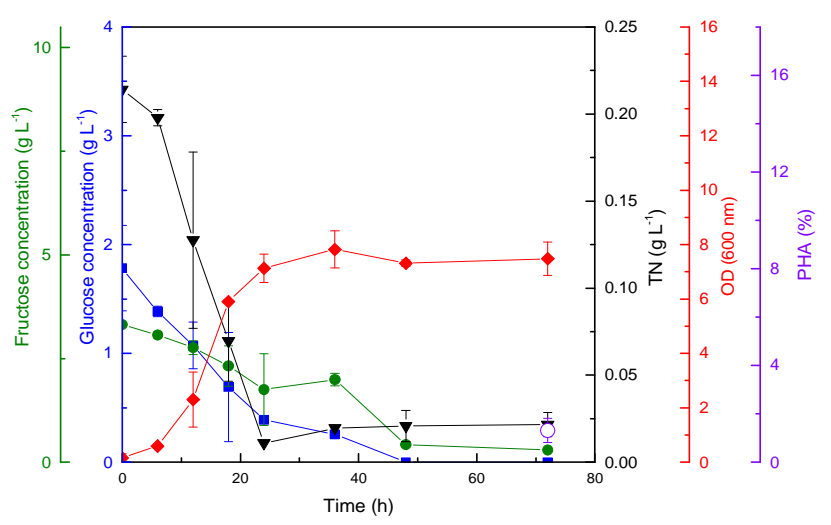

*All experiments were conducted in duplicate and data are presented as mean \pm standard deviation.

Fig. 2. Evolution of P. putida KT2440 in a) control, b) 0.4:1 AW:W ratio, c) 1:1 AW:W ratio and d) 1.5:1 AW:W ratio. ( $\circ \mathrm{OD}(600 \mathrm{~nm}), \nabla \mathrm{TN}$, ofructose, glucose, ○ PHA $(\%)$ ).

The control medium contained a slightly larger amount of carbohydrates than the medium prepared with 1:1 ratio and therefore, that led to a slightly higher OD and PHA concentration. The sugar consumption pattern was virtually the same in all the cultures. Glucose uptake was faster than fructose uptake leading to a depletion of glucose, followed by fructose, but as expected, higher sugar concentration led to higher OD. This behaviour agrees with the data obtained in other works. Löwe et al. ${ }^{[23]}$ observed the same trend with $P$. putida growing in a mixture of equal parts of glucose and fructose. Diniz et al. ${ }^{[19]}$ observed preferential consumption of glucose by $P$. putida IPT 046 when fed glucose and fructose mixtures.

Nitrogen exhaustion was reached in $24 \mathrm{~h}$ in all cases. It has been previously reported that production of PHAs requires nutrient limitation depending on the substrate used. In the case of using non-related precursors as carbon sources for PHA production, two factors are required for PHA accumulation in $P$. putida KT2440: a simultaneous nitrogen limitation with an excess of carbon ${ }^{[24]}$. In the apple waste juice prepared with 1:1 ratio and in the control media (Fig. 2 a) and c)), glucose was depleted between 18 and $24 \mathrm{~h}$ of fermentation, but OD values continued increasing until $72 \mathrm{~h}$ of fermentation due to the presence of fructose. In the apple waste juice prepared with ratios $0.4: 1$ and 1.5:1, the sugar concentration was much lower, so depletion occurred sooner and 
consequently the OD experienced a stop after $24 \mathrm{~h}$ of fermentation (Fig. 2 b) and d)).

394 Almost no PHA synthesis was detected in $P$. putida grown on the media prepared with

$395 \quad 0.4: 1$ and 1.5:1 ratios, likely due to their being insufficient carbon source remaining by

396 the $24 \mathrm{~h}$ mark. However, in the control and the media prepared with 1:1 ratio, $15 \pm 2.5$

397 and $14.5 \pm 2.5 \%$ of PHA accumulation was obtained, respectively. These results

398 suggest that glucose was consumed during the growth of $P$. putida, while fructose was

399 used by the bacteria mainly for PHA biosynthesis. In this experiment, maximum values

400 of total weight at $72 \mathrm{~h}(\mathrm{DCW})\left(3.7 \pm 0.47 \mathrm{~g} \mathrm{~L}^{-1}\right)$, PHA yield $\left(0.39 \pm 0.02 \mathrm{~g} \mathrm{~L}^{-1}\right)$ and

401 PHA accumulation $(14.5 \pm 1.9 \%)$ were obtained with $\mathrm{AW}: \mathrm{W}$ ratio $1: 1$. Therefore, after

402 analyzing the effect of different $\mathrm{AW}: \mathrm{W}$ ratios on the growth of $P$. putida, 1:1 ratio was

403 chosen as the working ratio for a second experiment.

404

405 In the second experiment, more apple waste medium was prepared and a higher

406 concentration of sugars was obtained compared to the previous batch due to the

407 heterogeneity of the apple waste medium, hence total carbohydrate of $15 \pm 3 \mathrm{~g} \mathrm{~L}^{-1}$ was

408 obtained with 1:1 AW:W ratio with these cider by-products. In order to increase the

409 PHA production a batch feeding strategy was employed using the same apple waste

410 juice medium supplemented with salts, and it was added into the cultures. This extra

411 feed was added at different cultivation times: at $12 \mathrm{~h}$ (before nitrogen depletion,

412 experiment $\mathrm{A}$ ), at $24 \mathrm{~h}$ (at the onset of nitrogen depletion, experiment $\mathrm{B}$ ) and $48 \mathrm{~h}$ (after

413 nitrogen depletion, experiment C). Each experiment was conducted in duplicate and

414 total nitrogen, glucose and fructose concentration and cell biomass were measured

415 during $96 \mathrm{~h}$ of cultivation. These results are displayed in Fig. 3, where the horizontal

416 dotted lines indicate the cultivation times at which the extra feed was added. Biomass

417 and product yields, as well as specific growth rate and maximum PHA content (at $96 \mathrm{~h}$ )

418 were calculated and the results are shown in Table 2. 
a)

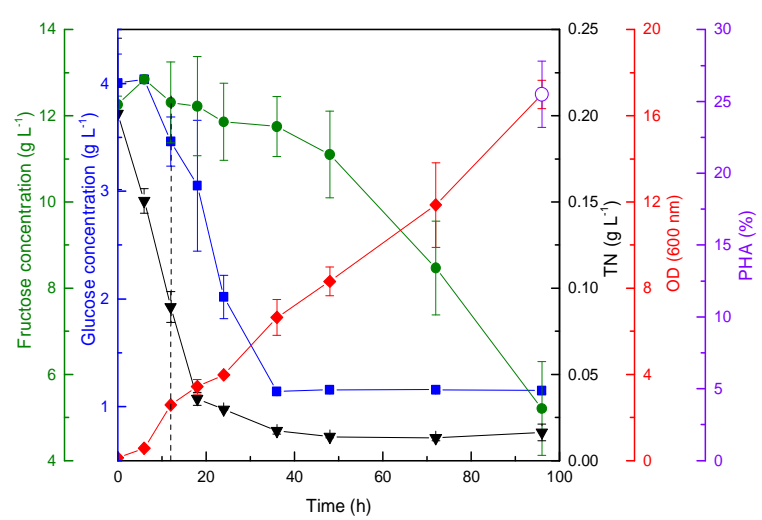

c)

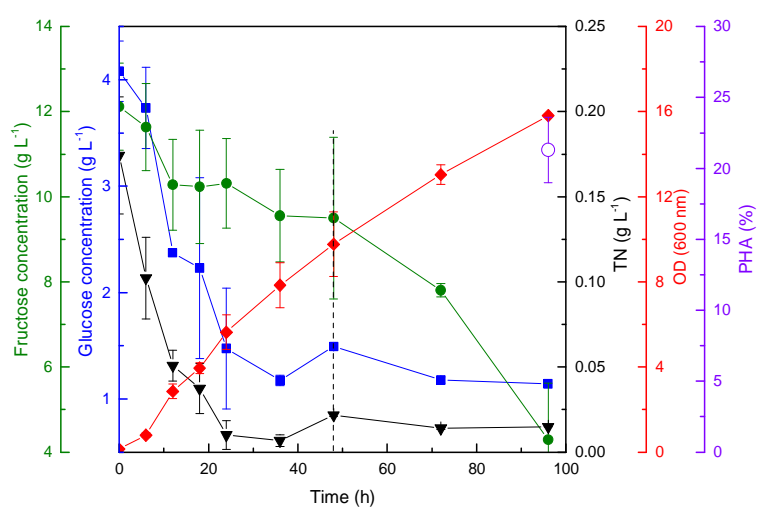

b)

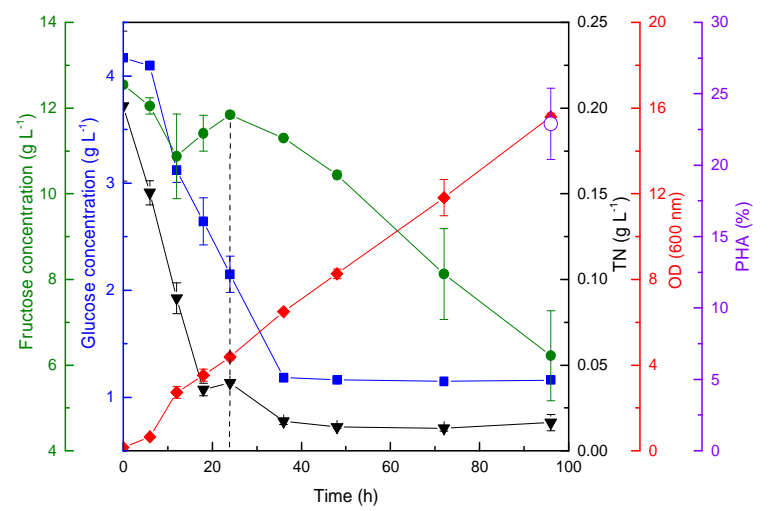

*All experiments were conducted in duplicate and data are presented as mean \pm standard deviation.

Fig. 3. Evolution of $P$. putida KT2440 in apple waste media after $96 \mathrm{~h}$ following a batch feeding strategy. a) experiment A, b) experiment B and c) experiment $\mathrm{C}$ (dotted lines indicate the cultivation times at which the extra feed was added $)(\diamond \mathrm{OD}(600 \mathrm{~nm}), \nabla \mathrm{TN}$, ofructose, aglucose, $\circ$ PHA (\%)).

421

422

423

424

425

426

Table 2. PHA accumulation and growth kinetic parameters determined in apple waste cultures prepared with $1: 1(\mathrm{AW}: \mathrm{W})$ ratio following batch feeding strategy at different cultivation times.

\begin{tabular}{|c|c|c|c|}
\hline & \multicolumn{3}{|c|}{ Experiment } \\
\hline & $\mathbf{A}$ & B & C \\
\hline$\mu_{\max }\left(\mathrm{h}^{-1}\right)$ & $0.24 \pm 0.01$ & $0.24 \pm 0.01$ & $0.25 \pm 0.01$ \\
\hline$Y_{X / S}\left(\mathrm{~g} \mathrm{~g}^{-1}\right)$ & $0.28 \pm 0.02$ & $0.31 \pm 0.05$ & $0.18 \pm 0.10$ \\
\hline$Y_{P / S}\left(\mathrm{~g} \mathrm{~g}^{-1}\right)$ & $0.11 \pm 0.02$ & $0.09 \pm 0.02$ & $0.07 \pm 0.02$ \\
\hline $\mathrm{DCW}^{96 \mathrm{~h}}\left(\mathrm{~g} \mathrm{~L}^{-1}\right)$ & $4.33 \pm 0.57$ & $4.02 \pm 0.21$ & $3.75 \pm 0.07$ \\
\hline PHA $^{96 h}\left(\mathrm{~g} \mathrm{~L}^{-1}\right)$ & $1.10 \pm 0.04$ & $0.93 \pm 0.10$ & $0.80 \pm 0.10$ \\
\hline $\mathrm{PHA}^{96 \mathrm{~h}}(\%)$ & $25.50 \pm 2.30$ & $22.90 \pm 2.50$ & $21.30 \pm 2.30$ \\
\hline
\end{tabular}

Hmax, maximum specific growth rate; YX/S, yield coefficient of biomass on substrate (glucose+fructose) conversion to biomass; $Y \mathrm{P} / \mathrm{S}$, yield coefficient of substrate conversion to PHA. Experiments were conducted in duplicate and data are presented as mean \pm standard deviation. 
PHA content and yield tended to be higher when the addition of the extra feed was made during the early stages of bacterial growth. This could be due to the fact that the most active growth of microorganisms occurred before $20 \mathrm{~h}$ of fermentation so the greater availability of substrate and nutrients at this stage possibly stimulated the production of higher cell concentrations with concurrent PHA storage. Although in these experiments initial carbohydrate concentrations are higher than in the previous experiments, it can be concluded that a fed batch cultivation can provide the solution to give a higher final product concentration. This experiment could help to design a strategy for a future optimization of the process in a bioreactor since different feeding strategies can be followed to increase the cell biomass and volumetric productivity ${ }^{[17]}$. Follonier et al. ${ }^{[22]}$ obtained a polymer accumulation of $23.3 \%$ using Solaris grape hydrolyzed pomace and waste frying oil in bioreactor experiments with $P$. resinovorans. In this work, when the extra feed was added at $12 \mathrm{~h}$ of fermentation a PHA accumulation of $25.5 \pm 2.3 \%$ was obtained. In this case no PHA precursors have been added to increase the production of the polymer and no pre-treatment of the raw material has been performed so the results indicate that cider by-products are a promising raw material for PHA production.

In terms of sugar consumption, fructose uptake was slower than glucose uptake, but both were metabolized simultaneously, as observed in the previous experiment. Glucose concentration was reduced by $72-73 \%$ while fructose concentration was reduced between 58 and $64 \%$. The maximum growth specific rates obtained in this work were lower than the values obtained by Follonier et al. ${ }^{[22]}$ using hydrolyzed pomaces of different fruits i.e. apricots, cherries and grapes $\left(\mu_{\max }\right.$ 0.85-0.60) and Borrero-de Acuña et al. ${ }^{[25]}$ using glucose as carbon source $\left(\left(\mu_{\max } 0.56\right)\right.$ for $P$. putida KT2440. Diniz et al. ${ }^{[19]}$ obtained maximum specific growth rates on glucose $(0.63-0.65)$ and fructose (0.26-0.20) with total glucose and fructose concentrations between 10 and $20 \mathrm{~g} \mathrm{~L}^{-1}$ in bioreactor experiments with $P$. putida IPT 046. In this context, Sawyer et al. ${ }^{[26]}$ reported that when species of Pseudomonas were grown in D-fructose as the main or sole carbon source, high doubling times were observed compared to other carbon sources, such as succinate. In these apple waste juices, fructose is one of the main carbon sources, and although everything indicates that glucose has been the main sugar for the bacterial growth, a small fraction of fructose has also been consumed in the early stages of the fermentation process so this probably had an effect in the growth rates leading to lower values compared to other works. However, the yield values of biomass $\left(Y_{X / S}\right)$ and PHA production $\left(Y_{P / S}\right)$ of this work (Table 2) resulted in the range of the ones obtained by Borrero-de Acuña et al ${ }^{[25]}$ with $P$. putida KT2440 and some $P$. putida mutant strains for the improvement of PHA production using glucose as sole carbon source in batch cultures. They obtained values of $Y_{X / S}$ between 0.21 and 0.25 and $Y_{P / S}$ values between 0.05 and 0.11 . These results contribute to support the assumption that in this work the bacterial growth is mainly derived from glucose and that the substrate conversion to PHA derives from the fructose consumption after nitrogen depletion. The results obtained in this work prove that using only waste-derived media, i.e. by-products of cider production, which consist of a heterogeneous mixture of sugars, is a viable solution for an acceptable production of PHA.

\subsection{PHA polymer structural characterization}


Biosynthesised PHA was extracted from the biomass obtained in the second experiment as described previously and characterized by different techniques to evaluate its possible film applications in different fields. The PHA film was optically transparent with yellowish colour (Fig. 1 b)).

GC-MS analysis was used to identify PHA monomer composition of the 3hydroxyalkanoate methyl esters prepared by total methanolysis and compared with standards. The synthesized PHA was composed by 3-hydroxyhexanoate $\left(3 \mathrm{HH}, \mathrm{C}_{6}\right), 3-$ hydroxyoctanoate $\left(3 \mathrm{HO}, \mathrm{C}_{8}\right)$, 3-hydroxydecanoate $\left(3 \mathrm{HD}, \mathrm{C}_{10}\right)$, 3-hydroxydodecanoate (3HDD, $\left.\mathrm{C}_{12}\right), \quad 3$-hydroxydodecenoate $\left(3 \mathrm{HDD}_{(=)}, \mathrm{C}_{12=}\right)$ and traces of 3hydroxytetradecenoate $\left(3 \mathrm{HTD}_{(=)}, \mathrm{C}_{14=}\right)$ (Fig. S1). The molar composition (\%) of each monomer was found to be: $3.19 \% 3 \mathrm{HH}, 23.43 \% 3 \mathrm{HO}, 60.90 \% 3 \mathrm{HD}, 6.94 \% \mathrm{HDD}$, $4.76 \% \mathrm{HDD}_{(=)}$and $0.77 \% \mathrm{HTD}_{(=)}$. $3 \mathrm{HD}$ was the predominant compound of this polymer, followed by $3 \mathrm{HO}$. The monomeric composition was the typical observed by other authors using sugars as carbon source and Pseudomonas strains ${ }^{[2,4]}$. The composition of unsaturated monomers $3 \mathrm{HDD}\left(\mathrm{C}_{12=}\right)$ and $3 \mathrm{HTD}\left(\mathrm{C}_{14=}\right)$ was established by comparing their mass spectra with that reported in the literature ${ }^{[2,4,27-29]}$. The position of the double bonds is discussed below and established taking into account the results of ${ }^{13} \mathrm{C}$ and ${ }^{1} \mathrm{H} \mathrm{NMR}$ analysis.

The chemical structure of the mcl-PHA was investigated using carbon $\left({ }^{13} \mathrm{C}\right)$ and proton $\left({ }^{1} \mathrm{H}\right)$ NMR analysis and the resultant spectra are gathered in Fig. 4 a) and b), respectively. Both NMR peak assignments were carried out comparing these results with previously literature reported by other authors ${ }^{[2,4,28,30]}$. The sequence structure proposed for the mcl-PHA produced by Pseudomonas putida KT2440 in cider apple residues is represented in Fig.5, where the carbons and protons are indicated with numbers and letters, respectively.

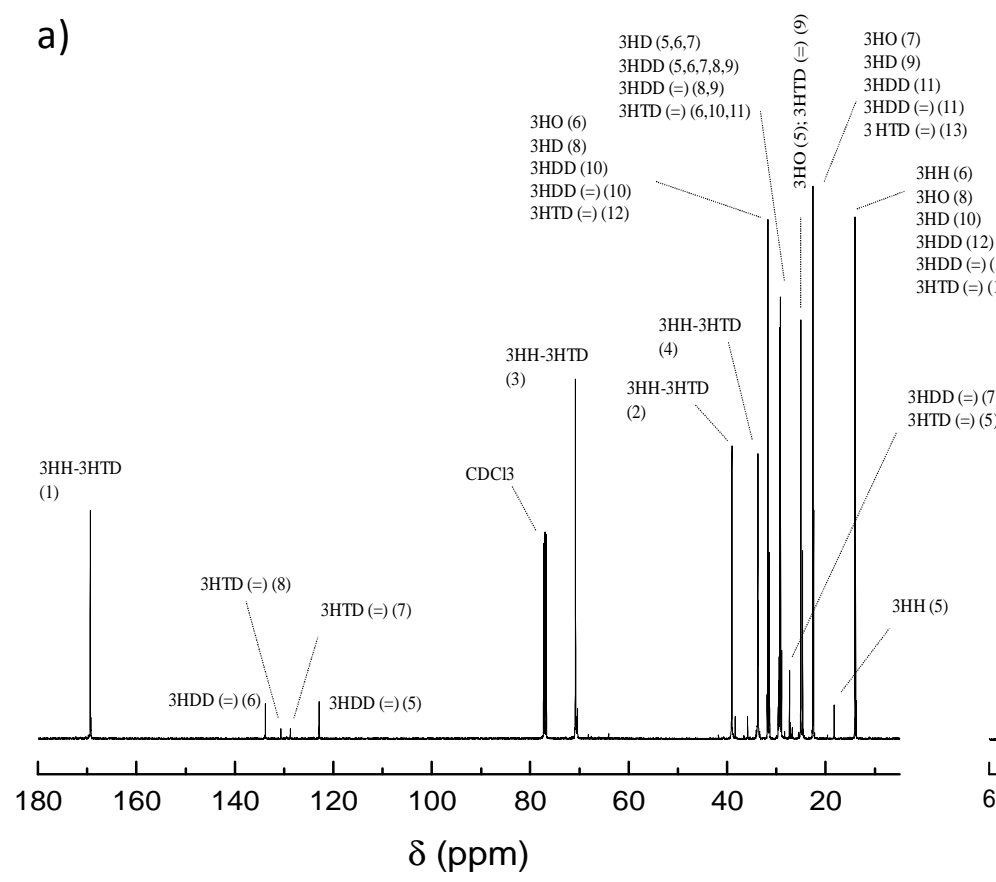

b) 


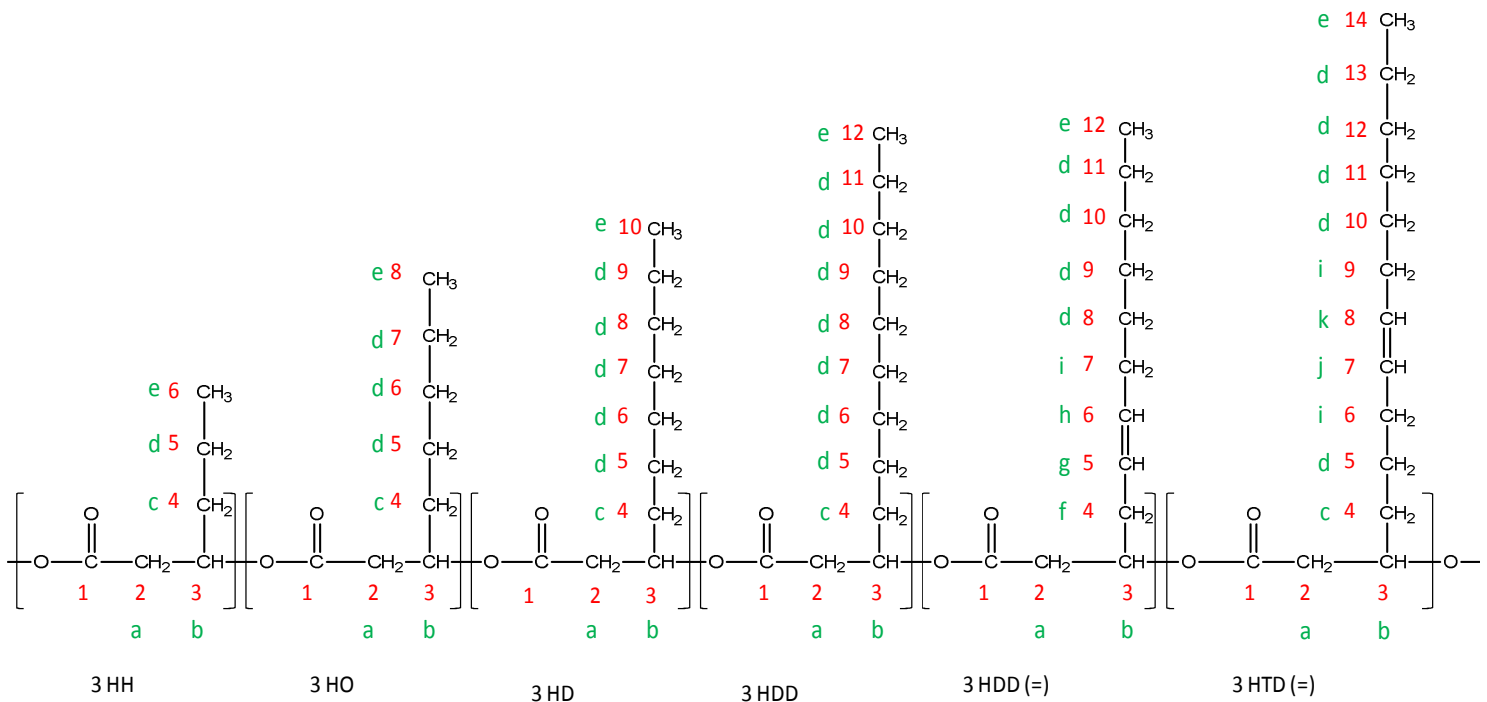

Fig. 5. Representative sequence structure of mcl-PHA synthesized by P. putida KT2440.

Fig. 4 a) displays the ${ }^{13} \mathrm{C}$ NMR spectrum of the PHA produced. All monomers were sharing similar chemical shifts for the major anomeric carbon, $C_{1},(169.35 \mathrm{ppm})$ and $\mathrm{C}_{2}$ (around 39-38 ppm), $\mathrm{C}_{3}$ (around 70-71 ppm) and $\mathrm{C}_{4}$ (around 33-36 ppm). The methyl groups located at the end of the chains of the monomers correspond to the chemical shifts detected between 13-14 ppm. The chemical shifts located between 120 and 140 ppm indicate the presence of unsaturated carbons. Two major signals at 122.9 and 133.8 ppm were observed which are assigned to olefinic carbons. These correspond to the double bond between $\mathrm{C}_{5}$ and $\mathrm{C}_{6}$, respectively, of 3HDD units. Additionally, two minor olefinic signals were observed at 128.7 and $130.6 \mathrm{ppm}$, corresponding to the presence of the double bond between $\mathrm{C}_{7}$ and $\mathrm{C}_{8}$ of 3 HTD units. (Table $\mathrm{S1}$ ).

Additionally, ${ }^{1} \mathrm{H}$ NMR spectrum is shown in Fig. 4 b). The protons next to carboxyl and hydroxyl groups ( $\mathrm{a}$ and $\mathrm{b}$ ) are assigned to the signals centered at 2.54 and $5.19 \mathrm{ppm}$, respectively. The first $\mathrm{CH}_{2}$ of the saturated alkane chain (c) corresponds to the signal centered at $1.59 \mathrm{ppm}$. Small peaks at 5.54, 5.52, 5.37 and $5.30 \mathrm{ppm}(\mathrm{h}, \mathrm{k}, \mathrm{g}, \mathrm{j})$ confirm the presence of side chains containing unsaturated groups. Finally, the remaining protons of methylene (d) and terminal methyl (e) groups are assigned to the peaks centered at 1.27 and $0.88 \mathrm{ppm}$, respectively.

Molecular weight and distribution of the PHA copolymer were determined by GPC. Weight average molecular weight $\left(\bar{M}_{w}\right)$ and number average molecular weight $\left(\bar{M}_{n}\right)$ of the PHA were found to be $4.7 \times 10^{4}$ and $2.1 \times 10^{4}$, respectively, and the polydispersity index (PI) was 2.2. It has been previously reported that the molecular weight of the PHAs depends on four factors which are (1) concentration of PHA synthase, (2) occurrence of the chain transfer reaction, (3) catalytic activity of PHA synthase and (4) simultaneous degradation of PHA during biosynthesis ${ }^{[31,32]}$. The molecular weight values obtained in this work are slightly lower than those obtained by other authors using Pseudomonas strains and sugars as carbon source ${ }^{[6,41]}$ and similar to 
545 others obtained using Pseudomonas strains and glycerol as the main substrate ${ }^{[5,38]}$. 546 Nevertheless, it should be noted that the eluent used for the molecular weight 547 measurements influences the values obtained and in three of the four cases chloroform 548 was used as the elution solvent, while in this case THF was used. The molecular weight 549 is directly related to the mechanical strength, so usually for thermoplastic polymers such 550 as PHB, high molecular weight is preferred. Nevertheless, mcl-PHAs which present 551 lower molecular weights, have potential applications in the biomedical field such as the 552 development of polymeric nanoparticles for the delivery of active compounds in the 553 human body, for heart valves and cardiovascular implants, as well as coatings, adhesive materials or biding agents for polymers ${ }^{[33-35]}$.

Usually, mcl-PHAs present elastomeric behaviour, i.e. present low crystallinity, low tensile strength and high elongation at break with glass transition temperatures $\left(\mathrm{T}_{\mathrm{g}}\right)$ ranging from -50 to $-25^{\circ} \mathrm{C}$ and melting temperatures $\left(\mathrm{T}_{\mathrm{m}}\right)$ ranging from 40 to $65^{\circ} \mathrm{C}^{[5]}$. Generally, the crystallization is slow and some copolymers do not crystallize at all, so no $\mathrm{T}_{\mathrm{m}}$ is observed. The production of amorphous polymers can be ascribed to the incorporation of unsaturated monomers and long chains, factors which can perturb the packing for crystallization ${ }^{[36]}$. It is worth mentioning that for in vivo applications in the biomedical field, the enzymes that degrade PHB are less efficient for the polymer in its amorphous state. For this reason, mcl-PHAs are more suitable than PHB, which has high crystalline nature. In the thermal analysis of the mcl-PHA (Fig. S2) the presence of two transitions was observed, one at low temperature associated to glass transition $\left(\mathrm{T}_{\mathrm{g}}=\right.$ $-42{ }^{\circ} \mathrm{C}$ ) and second one at higher temperature associated to melting process. The endotherm observed around $47^{\circ} \mathrm{C}$ was related to the melting of the crystalline phase. This result was in accordance with the result obtained in the FTIR spectrum, where bands associated to the crystallinity of the polymer were observed due to a sharpening of the carbonyl band at $1726 \mathrm{~cm}^{-1}$ (Fig. S3). Moreover, the thermomechanical behaviour of the mcl-PHA film was studied by analyzing the evolution of storage modulus ( $\mathrm{E}^{\prime}$ ) and Tan Delta (Tan $\delta$ ) as a function of temperature (Fig. S2). At low temperatures the PHA showed high $\mathrm{E}^{\prime}(\sim 360 \mathrm{MPa})$ in the glassy state. At higher temperatures, a decrease in $E^{\prime}$ happened related to the glassy transition region and Tan $\delta$ curve showed a maximum which was related to the mechanical relaxation $(\alpha)$ of the PHA, associated with the glassy transition temperature $\left(\mathrm{T}_{\mathrm{g}}=-32^{\circ} \mathrm{C}\right)$. The $\mathrm{E}^{\prime}$ value at room temperature was low, so this mcl-PHA is a very soft, elastic and slightly sticky material. With these features, this mcl-PHA could be suitable to use it in blends with crystalline polymers that are difficult to process in a common extruder such as PHB. In the area of agriculture, mcl-PHAs have been used in blends with PHB to develop Nodax ${ }^{\mathrm{TM}}$, which can be used to manufacture biodegradable mulch films to use as coatings for fertilizers, insecticides and herbicides ${ }^{[37]}$. Moreover, this mcl-PHA could be suitable for adhesive applications in friendly packaging. In fact, mcl-PHAs have been used for the development of hot melt biodegradable adhesives ${ }^{[38,39]}$.

\section{CONCLUSIONS}

The technical feasibility of using cider by-products for PHA production by $P$. putida KT2440 has been demonstrated. The raw material contained glucose and fructose, both of which could be utilized in PHA production. Shake flask experiments revealed a higher optical density and biopolymer accumulation at higher sugar content, reaching a PHA concentration of $1.1 \mathrm{~g} \mathrm{~L}^{-1}$ at a PHA accumulation of $25.5 \%$ with the addition of 
extra feed at $12 \mathrm{~h}$ of fermentation. Further, the biosynthesized PHA was extracted from the biomass and monomer composition, chemical structure, molecular weight, thermal and thermomechanical properties were analysed. The polymer was found to be a mclPHA with a composition of different monomers containing from 6 to 14 carbons with saturated and unsaturated chains. This composition results in an elastomeric behaviour, being the material soft, elastic and sticky at room temperature with potential applications in the biomedical field as well as in adhesives, or for agricultural purposes. Although further bioprocess engineering development is required to make the process industrially viable, cider by-products are a promising carbon source for mcl-PHA production, which in turn could be used in the processing of value-added products.

\section{ACKNOWLEDGEMENTS}

The authors thank for the financial support from the Spanish Ministry of Economy and Competitiveness (MINECO) (MAT2016-76294-R) and the Basque Government in the frame of Grupos Consolidados (IT-776-13). We are also grateful for the technical support provided by SGIker of UPV/EHU and European funding (ERDF and ESF). Leire Urbina wishes to acknowledge the Basque Government for its PhD grant PIF PRE_2014_1_371 and for the EGONLABUR grant for predoctoral internships. 


\section{REFERENCES}

[1] Y. Ke, X. Y. Zhang, S. Ramakrishna, L. M. He, G. Wu, Synthetic routes to degradable copolymers deriving from the biosynthesized polyhydroxyalkanoates: A mini review, Express. Polym. Lett. 10 (2016) 36-53.

[2] G. Huijberts, G. Eggink, P. de Waard, G. W. Huisman, B. Witholt, Pseudomonas putida KT2442 Cultivated on glucose accumulates Poly(3Hydroxyalkanoates) consisting of saturated and unsaturated monomers. Appl. Environ. Microbiol. 58 (1992) 536-544.

[3] A. Muangwong, T. Boontip, J. Pachimsawat, S. C. Napathorn, Medium chain length polyhydroxyalkanoates consisting primarily of unsaturated 3-hydroxy-5-cisdodecanoate synthesized by newly isolated bacteria using crude glycerol. Microb. Cell. Fact. 15 (2016) 1-17.

[4] R. J. Sánchez, J. Schripsema, L. F. da Silva, M. K. Taciro, J. G.C. Pradella, J.G.C. Gomez, Medium-chain-length polyhydroxyalkanoic acids (PHAmcl) produced by Pseudomonas putida IPT 046 from renewable sources. Eur. Polym. J. 39 (2003) 1385-1394.

[5] E. Renard, G. Vergnol, V. Langlois, Adhesion and proliferation of human bladder RT112 cells on functionalized polyesters. IRBM. 32 (2009) 214-220.

[6] X. Yang, K. Zhao, G-Q. Chen, Effect of surface treatment on the biocompatibility of microbial polyhydroxyalkanoates. Biomaterials. 23 (2002) 1391-1397.

[7] R. Rai, T. Keshavarz, J.A. Roether, A.R. Boccaccini, I. Roy, Medium chain length polyhydroxyalkanoates, promising new biomedical materials for the future. Mater. Sci. Eng. R. Rep. 72 (2011) 29-47.

[8] R. Rai, J.A. Roether, J.C. Knowles, N. Mordan, V. Salih, I.C. Locke, M.P. Gordge, A. McCormick, D. Mohn, W.J. Stark, T. Keshavarz, A.R. Boccaccini, I. Roy, Highly elastomeric poly(3-hydroxyoctanoate) based natural polymer composite for enhanced keratinocyte regeneration. Int. J. Polym. Mater. 66 (2017) 326-335.

[9] Z. A. Raza, S. Abid, I. M. Banat, Polyhydroxyalkanoates: Characteristics, production, recent developments and applications. Int. Biodeterior. Biodegradation. 126 (2018) 45-56.

[10] Y. K. Leong, P. L. Show, C. W. Ooi, T. C. Ling, J. C-W. Lan, Current trends in polyhydroxyalkanoates (PHAs) biosynthesis: Insights from the recombinant Escherichia coli. J. Biotechnol. 180 (2014) 52-65.

[11] C. Nielsen, A. Rahman, A. Ur Rehman, M. K. Walsh, C. D. Miller, Food waste conversion to microbial polyhydroxyalkanoates. Microb. Biotechnol. 10 (2017) 1338-1352. 
[12] S.K.S. Patel, P. Kumar, M. Singh, J-K. Lee, V.C. Kalia, Integrative approach to produce hydrogen and polyhydroxybutyrate from biowaste using defined bacterial cultures. Bioresour. Technol. 176 (2015) 136-141.

[13] Y. Dineiro, B. Valles, A. Picinelli, Phenolic and antioxidant composition of byproducts from the cider industry: Apple pomace. Food. Chem. 117 (2009) 731-73.

[14] M. Kruczek, D. Gumul, M. Kačániová, E. Ivanišhová, J. Mareček, H. Gambuś, Industrial apple pomace by-products as a potential source of pro-health compounds in functional food. J. Microbiol. Biotechnol. Food. Sci. 7 (2017) 22-26.

[15] R. G. Lageveen, G. W. Huisman, H. Preusting, P. Katelaar, G. Eggink, B. Witholt, Formation of polyesters by Pseudomonas oleovorans: effect of substrates on formation and composition of poly-(R)-3-hydroxyalkanoates and poly-(R)-3hydroxyalkenoates. Appl. Environ. Microbiol. 54 (1998) 2924-2932.

[16] X. Jiang, , J. A. Ramsay, B. A. Ramsay, Acetone extraction of mcl-PHA from Pseudomonas putida KT2440. J. Microbiol. Methods. 67 (2006) 212-219.

[17] R. Davis, G. Duane, S.T. Kenny, F. Cerrone, M. W. Guzik, R. P. Babu, E. Casey, K. E. O’Connor, High cell density cultivation of Pseudomonas putida KT2440 using glucose without the need for oxygen enriched air supply. Biotechnol. Bioeng. 112 (2015) 725-733.

[18] I. F. Escapa, C. del Cerro, J. L. García, M. A. Prieto, The role of GlpR repressor in Pseudomonas putida KT2440 growth and PHA production from glycerol. Environ. Microbiol. 15 (2013) 93-110.

[19] S. C. Diniz, M. K. Taciro, J. G. C. Gomez, J. G. C. Pradella, High-cell-density cultivation of Pseudomonas putida IPT 046 and medium-chain-length polyhydroxyalkanoate production from sugarcane carbohydrates. Appl. Biochem. Biotechnol. 119 (2004) 51-70.

[20] A.P. Lobo, M.J. Antón-Díaz, R.P. Bedriñana, O. F. García, R. Hortal-García, B.S. Valles, Chemical, olfactometric and sensory description of single-variety cider apple juices obtained by cryo-extraction. LWT-Food. Sci. Technol. 90 (2018) 193200.

[21] T. Pires, M.I. Dias, L. Barros, M.J. Alves, M.B. Oliveira, C. Santos-Buelga, I. Ferreira, Antioxidant and antimicrobial properties of dried Portuguese apple variety (Malus domestica Borkh. cv Bravo de Esmolfe). Food. Chem. 240 (2018) 701-706.

[22] S. Follonier, M. S. Goyder, A-C. Silvestri, S. Crelier, F. Kalman, R. Riesen, M. Zinn, Fruit pomace and waste frying oil as sustainable resources for the bioproduction of medium-chain-length polyhydroxyalkanoates. Int. J. Biol. Macromol. 71 (2014) 42-52.

[23] H. Löwe, L. Schmauder, K. Hobmeier, A. Kremling, K. Pflüger-Grau, Metabolic engineering to expand the substrate spectrum of Pseudomonas putida toward sucrose. Microbiologyopen. 6 (2017) e00473. 
[24] S. Follonier, S. Panke, M. A. Zinn, Reduction in growth rate of Pseudomonas putida KT2442 counteracts productivity advances in medium-chain-length polyhydroxyalkanoate production from gluconate. Microb. Cell. Fact. 10 (2011) 25.

[25] J. M. Borrero-de Acuña, A. Bielecka, S. Häussler, M. Schobert, M. Jahn, C. Wittmann, D. Jahn, I. Poblete-Castro, Production of medium chain length polyhydroxyalkanoate in metabolic flux optimized Pseudomonas putida. Microb. Cell. Fact. 13 (2014) 88.

[26] M.H. Sawyer, P. Baumann, L. Baumann, S.M. Berman, J.L. Cánovas, H. Berman, Pathways of D-fructose catabolism in species of Pseudomonas. Arch. Microbiol. 112 (1977) 49-55.

[27] D-K. Kang, C-R. Lee, S.H. Lee, J-H. Bae, Y-K. Park, Y. H. Rhee, B. H. Sung, J-H. Sohn, Production of polyhydroxyalkanoates from sludge palm oil using Pseudomonas putida S12. J. Microbiol. Biotechnol. 27 (2017) 990-994.

[28] M. Kato, H.J. Bao, C.K. Kang, T. Fukui, Y. Doi, Production of a novel copolyester of 3-hydroxybutyruc acid and medium-chain-length 3-hydroxyalkanoic acids by Pseudomonas sp. 61-3 from sugars. Appl. Microbiol. Biotechnol. 45 (1996) 363-370.

[29] E.Y. Lee, C.Y. Choi, Gas chromatography-mass spectrometric analysis and its application to a screening procedure for novel bacterial polyhydroxyalkanoic acids containing long chain saturated and unsaturated monomers. J. Ferment. Bioeng. 4 (1995) 408-414.

[30] F. Pappalardo, M. Fragalà, P. G. Mineo, A. Damigella, A. F. Catara, R. Palmeri, A. Rescifina, Production of filmable medium-chain-lenght polyhydroxyalcanoate produced from glycerol by Pseudomonas Mediterranea. Int. J. Biol. Macromol. 65 (2014) 89-86.

[31] M. V. Reddy, Y. Mawatari, R. Onodera, Y. Nakamura, Y. Yajima, Y-C. Chang, Polyhydroxyalkanoates (PHA) production from synthetic waste using Pseudomonas pseudoflava: PHA synthase enzyme activity analysis from $P$. pseudoflava and P. Palleronii. Bioresour. Technol. 234 (2017) 99-105.

[32] T. Tsuge, Fundamental factors determining the molecular weight of polyhydroxyalkanoate during biosynthesis. Polym. J. 48 (2016) 1051-1057.

[33] P.G. Ward, G. Roo, K.E. O'Connor, Accumulation of polyhydroxyalkanoate from styrene and phenylacetic acid by Pseudomonas putida CA-3. Appl. Environ. Microbiol. 71 (2005) 2046-2052.

[34] D.M. Panaitescu, I. Lupescu, A.N. Frone, I. Chiulan, C. A. Nicolae, V. Tofan, A. Stefaniu, R. Somoghi, R. Trusca, Medium Chain-Length Polyhydroxyalkanoate Copolymer Modified by Bacterial Cellulose for Medical Devices. Biomacromolecules. 18 (2017) 3222-3232. 
[35] K. A. Ishak, M. S. M. Annuar, Phase inversion of medium-chain-length poly-3hydroxyalkanoates (mcl-PHA)-incorporated nanoemulsion: effects of mcl-PHA molecular weight and amount on its mechanism. Colloid. Polym. Sci. 294 (2016) 1969-1981.

[36] J. Rydz, W. Sikorska, M. Kyulavska, D. Christova, Polyester-based (bio)degradable polymers as environmentally friendly materials for sustainable development. Int. J. Mol. Sci. 16 (2015) 564-596.

[37] I. Noda, P.R Green, M.M. Satkowski, L.A. Schechtman, Preparation and properties of a novel class of polyhydroxyalkanoate copolymers. Biomacromolecules, 6 (2005) 580-586.

[38] I. Noda, Nonwoven materials comprising biodegradable copolymers. WO1997004036 A1. The Procter \& Gambre Company. 1997.

[39] R.S. Whitehouse, L. Zhong, S. Daughtry, Compositions comprising low molecular weight polyhydroxyalkanoates and methods employing same. US7094840 B2. Metabolix, Inc. 2006. 